\title{
Towards (more) integrity in academia, encouraging long-term knowledge creation and academic freedom
}

\author{
K. Akrivou ${ }^{1,2, *}$ \\ ${ }^{1}$ Henley Business School, University of Reading, Whiteknights, Reading RG6 6UD, UK, \\ ${ }^{2}$ Institute of Enterprise and Humanism, University of Navarre, 3100 Pamplona, Spain
}

\begin{abstract}
European researchers across heterogeneous disciplines voice concerns and argue for new paths towards a brighter future regarding scientific and knowledge creation and communication. Recently, in biological and natural sciences concerns have been expressed that major threats are intentionally ignored. These threats are challenging Europe's future sustainability towards creating knowledge that effectively deals with emerging social, environmental, health, and economic problems of a planetary scope. Within social science circles, however, the root cause regarding the above challenges has been linked with macro-level forces of neo-liberal ways of valuing and relevant rules in academia and beyond which we take for granted. These concerns raised by heterogeneous scholars in natural and the applied social sciences concern the ethics of today's research and academic integrity. Applying Bourdieu's sociology, there is little hope that intentional human agency may change the current habitus. Rather than attributing the replication of neo-liberal habitus in intentional agent and institutional choices, Bourdieu's work raises the importance of thoughtlessly internalised habits in human and social action. Accordingly, most action within a given paradigm (in this case, neo-liberalism) is understood as habituated, i.e. unconsciously reproducing external social fields, even ill-defined ways of valuing. This essay analyses these and how they may help critically analyse the current habitus surrounding research and knowledge production, evaluation, and communication and related aspects of academic freedom. Although it is acknowledged that transformation is not easy, this essay presents arguments and recent theory paths to suggest that change nevertheless may be a realistic hope once certain action logics are encouraged.
\end{abstract}

KEY WORDS: Integrity - Ethics · Habitus - Common good · Prosperity - History of science · Neo-liberalism $\cdot$ Sustainability

\section{INTRODUCTION AND OVERVIEW OF CRITIQUES ACROSS THE SCIENCES}

European scientists and researchers increasingly network across many heterogeneous disciplines to engage in activism on how to affect a brighter future for science and scientific production and knowledge creation in Europe.

Recently, in biological and natural sciences it has been convincingly argued that major threats are

\footnotetext{
${ }^{*}$ Corresponding author: k.akrivou@henley.reading.ac.uk
}

being ignored. These threats are challenging Europe's future sustainability to continue generating ground breaking new research capacity - one that can truly effectively deal with emerging social, environmental, health, and economic problems of a planetary scope. It has been suggested that this ignorance may be quite intentional (Moro-Martin 2014, Pauly 2014). I suggest that policy-makers at a national and EU level, and subordinate public sector research universities in Europe, are imposing politi-

() The author 2015. Open Access under Creative Commons by Attribution Licence. Use, distribution and reproduction are unrestricted. Authors and original publication must be credited. 
cal cycles valuing short-term research output, while their conception on what kind of knowledge and knowledge production is valued is inaccurate. Accordingly, the importance of nurturing long-term and ground-breaking research to deal with current challenges is being ignored because of defensive negligence, with instead a preference for adoption of myopic and not well thought out short-term instrumental strategies regarding institutional research evaluation and, of course, funding (Cimini et al. 2014, Moro-Martin 2014).

Like scholars in natural and environmental sciences, leading scholars in the applied social sciences, such as business, management and economics, have over time sharpened a critique of the role and the economics of university-based departments and business schools (for example, Pfeffer \& Fong 2002, 2004). The end of the mainstream assumptions and paradigms (Pfeffer \& Fong 2002) in which full legitimacy has been granted to a 'conventional' role being the mission of business and economics schools in universities has been predicted. Critiques have also focused on an increasingly conventional orientation since the 1980s in the applied social sciences towards research and knowledge production (Bennis \& O'Toole 2005, Ghoshal 2005, Chia \& Holt 2008). Like in the natural and environmental sciences, also in social sciences there has been for at least two decades now, a valuing of short-term orientation around how research and the fate of young and midcareer academics is being evaluated: simply put, instrumental research metrics and similar rules of esteem guide judgement of each publication's and each academic's worth. Also, pressures upon universities lead them to centrally allocate organisational and financial capital in order to compete well in the battle of reputation and rankings (Stergiou \& Tsikliras 2014) across other universities and across university departments (that mutually regard each other as 'competitors'). For these scholars, another key challenge is the very fragmentation of the scientific disciplines and their further fragmentation into 'manageable' economic units or departments (Mingers \& Willmott 2012, Akrivou \& Bradbury-Huang 2014). This is a conservative turn inspired by 'Tayloristic' approaches in early management theory advocating a 'scientific' approach to management, mainly emphasizing precise measurement and close monitoring and control of social and technical systems and resources (Boje 1993, Purser et al. 1995). This competitive, divisive and metrics-oriented morality negatively affects academic freedom and adversely hampers the shared ethic of humanity to search for truth and better theories and frameworks to affect a prosperous future for all at various levels.

\section{A NEO-LIBERAL HABITUS AND ITS EXPRESSION IN PRACTICES AFFECTING KNOWLEDGE CREATION, EVALUATION AND COMMUNICATION}

Within social science circles there is deeper critical attribution of the root cause of these problems, as they are seen linked with more macro-level forces with a causal role. Significant works see the root cause of all this linked with neo-liberalism, originating in von Hayek's thesis (Davies 2014). It can be summarised for the purpose of this article as the attempt to restrict and suppress genuine social and political valuing and decision-making originating 'naturally' in the process of engagement within collective social and scientific forces and communities who carefully think and research towards deliberately and organically chosen goals and directions. Instead, collective social and political valuing is being replaced by abstract and rule-based economic evaluation, guided by a surface-level adoption of metrics externally imposed; these are to be used as the standard against which to rate people and work to comply with impersonal and seemingly anonymous 'market forces' (Davies 2014.) It is worth noting that a connection is made between neoliberalist action, logic mechanics and neoliberalists' preferred morality, which in neo-liberal terms is seen to inspire an abstractly expressed 'new common good': the best results are believed to be produced via competition and antagonism (where a few would be 'winners'), rather than collaboration and co-creation as core virtues (Chomsky 1999, Sandel 2010, Davies 2014).

The moral concerns over the spreading of a neoliberal approach to virtue and the common goods and concerns about the coherence and integrity of key public, scientific and education institutions (Davies 2014) are overarching themes of the issues raised by a plurality of heterogeneous scholars in natural and social sciences regarding the ethics of today's research and academic integrity.

Applying Bourdieu's sociology (Bourdieu \& Waquant 1992, Bourdieu 2005) may be linked to the argument that change is impossible. Rather than attributing the replication of neo-liberal habitus in intentional agent and institutional choices, Bourdieu's work raises the importance of thoughtlessly internalised habits in human and social action. Accordingly, most action within a given paradigm (in this 
case, neo-liberalism) is understood as habituated, i.e. unconsciously reproducing external social fields, even ill-defined ways of valuing (Akrivou \& Todorow 2014). Habitus explains how human action concentrated in various social institutions, policy and political bodies is more likely to be reproductive of the neo-liberal economic and political values, rather than transformative. Current habitus in academia values narrow individualism, antagonism and separation, taking for granted practices as bureaucracy, managerialism and legitimising elite groups' power imbalances. Importantly, habitus refers to an individual's deeply ingrained and embodied habits of thought and action and it cumulatively replicates (at social group and individual person levels) social norms at mostly unconscious - and therefore repetitive-level (Akrivou \& Bradbury-Huang 2014, Akrivou \& Todorow 2014). Current habitus in academia is a multi-level concept (Akrivou \& Bradbury-Huang 2014): senior leadership, administrative staff, managers, senior and junior professors all play distinct roles that sustain a non-virtuous university, albeit with different degrees of influence. Therefore, Bourdieu's conception may explain the felt inertia and helplessness which science and knowledge producers experience within a neo-liberal field, as institutional and policy actors act and replicate policy values emerging directly from the internalisation of norms and values of a neo-liberal economic organisation.

Current habitus reproduces and fundamentally affects what assumptions we consider true on the very nature of knowledge (Chia \& Holt 2008) and knowing (Ghoshal 2005). Consequentially, following this argument, research organisation in universities in a neo-liberal field (system) of economic valuing (Greenwood 2012) unreflectively replicates university habitus. It values and monitors success against any externally imposed measures and conveniently avoids the duty to politically engage and interrogate if such measures may pose risks for long term prosperity, amplifying problematic dynamics in an economic paradigm that grows through depletion of social and natural capital (Akrivou \& BradburyHuang 2014). This habitus-field unsustainable relation has as implication that university and academic departments pursue ratings and reputation in a mono-dimensional and often narrowly instrumental way. Academic freedom and tenure accordingly mainly depend on one's capacity to follow kinds of research and research outputs which achieve short term ratings and impact. These are generally linked with established elites and ideas in research and knowledge, rather than the risk to generate new ways of thinking. New theories and ideas take longer until they are empirically tested and come to fruition, which seriously impedes their ongoing stream of funding and publications (Kuhn 2012, Moro-Martin 2014). Importantly, they are also engaged with a significant risk and vulnerability aspect of ground breaking research: to question and to collide with current and established theories, ways of valuing and ways of seeing the world.

Generally though, current habitus functions using moral relativism in a strangely dogmatic way. The adoption of moral relativism means that there is an avoidance by the most powerful sections of current habitus (mainstream policy makers, peer-reviewed journal editors, and university presidents/vice-chancellors) to acknowledge a simple objective truth throughout the history of science: that the cycles which researchers need to establish, test and modify new ground-breaking knowledge are long and entail uncertainty. Failure (by anyone and everyone) to acknowledge this objective truth regarding science means that myopic and anachronistic understandings on these matters become operating habits and remain unchallenged because it looks unnatural, or even 'heretic' to challenge these. Institutions and/or departments that develop reputation based on the current habitus or, ones that are increasing confidence in mastering and succeeding via the current 'rules' (in either rankings, or financial success terms) - but also institutions that have survival and academic quality and identity problems based on the same metrics - may be hardest to commit to substantial change, as it is neither rational nor easy or convenient to do so and transformation would disrupt the currently powerful coalitions in these institutions, including a few elite researchers enjoying the largest grants (Cimini et al. 2014). It is therefore this anachronistic habitus that ultimately needs to be transformed; but it takes intentional human virtuous action to transform it.

As noted, transformation at the level of ways of valuing is not easy. Habitus is linked with powerful economic interests that have a current vested interest in the perpetuation of the situation. Therefore, often there is also a latent narrowly self-interested and defensively (myopically) self-protective dimension linked to why universities (for instance) may be unwilling to support a new ethic as to how to nurture knowledge creation, and allow their research academics to inspire new theory lenses that can bring about solutions towards a more ethical and sustainable economy, until it is empirically and socially established. Universities are ultimately managed by 
human beings who may lack the virtue and character constancy to resist and transform effectively the neoliberal habitus; instead it is more convenient to replicate and try to score well based on existing rules and imposed metrics and performance criteria at institutional and research centre level. Especially since universities' existence often depends on a sustained governmental and private economic support to sustain their large and often unnecessarily complex bureaucratic structures, it may even be seen that neo-liberal, mainstream thinking in research administrators and senior university management is indeed more a virtue than a vice, when it comes to appointment decisions in senior management.

Within this habitus, the problem of academic integrity and academic freedom and tenure becomes a highly complex and strongly politicised issue, when it concerns academics and works which aim to question and transcend existing knowledge and takenfor-granted assumptions; especially when these are linked with a certain conventional orthodoxy of thinking within different academic sub-communities. Although overall, the value of evaluating research progress and research contribution may be a sine qua non condition for the promotion of good science, within a neo-liberal field the tendency to trust impersonal metrics is currently out of balance and in excess of what should be seen as 'normal'. It often actually works to hamper the right to academic freedom by discouraging academics to think, personally role model and teach knowledge that challenges prevailing orthodoxies of valuing, knowing, and of thinking, rather than to openly disagree and inquire. Often, it just works to encourage narrow researcher instrumental rationality choices to 'align' research with fashionable and mainstream ideas. Over time this works to discourage people from pursuing less fashionable and less mainstream research (which may attract less 'reputation' and image for the universities involved) or simply discourage independently led research, and encourage only sponsored research (i.e. by companies and other economic groups who wish to pay to see a certain research moving on, since often it takes at dozen or more years for a new scientific theory to be empirically proven and 'make it' to the acceptable mainstream).

At the heart of this is also the peer review and rating system by key leading journals, university departments, individual researchers and universities themselves. The resulting dynamics may result in the sciences and the social sciences in general, steadfastly becoming auto-poetically irrelevant (Flyvbjerg 2001); for example, their inability to change their position regarding research production and evaluation to respond to the surrounding real challenges facing economy and society, beyond short-term solutions that may enable them to maintain wealth and technical advances for some political, economic and social elites, while remaining unconcerned with how to generate substantial knowledge that can sustainably affect well-being at individual, natural system and community levels.

\section{A REAL POSSIBILITY TO TRANSFORM NEO- LIBERAL HABITUS: THEORY ADVANCES AND RECOMMENDATIONS FOR CHANGE}

The common denominator across all these heterogeneous critiques cited previously is that all 'see' that these more macro- and policy-related exogenous forces affect the ways of valuing research and researchers within universities and university departments. They affect 'our' values and assumptions which guide the decision making-process, and rules regarding what ideas are being promoted, how research is being organized, and types of work which is being nurtured and spread versus types of work which are being considered 'high risk' and less in synch with the held assumptions. This matter potentially involves a range of crucial academic faculties (in biology, medicine, cognitive science, physics, climate and environmental studies, and also in the applied social sciences such as business and economics.) However, it is across all sciences, where knowledge produced may indeed impact the current and the future capacity of societies and economies to creatively and effectively cope with current global challenges impacting society, the economy and life on the planet more broadly.

We must therefore reimagine the ways in which scientific knowledge production can once again genuinely search for new knowledge beyond what we know, so it can contribute to the societal flourishing for the many. This means concretely that to revive current academia, a new sense of a more unified natural and social science in Europe may be required to defend an unmoderated degree of fragmentation of academic disciplines (Greenwood 2012, Akrivou \& Bradbury-Huang 2014). Excellence in the new habitus must be accessible to diverse research voices, groups and researchers as it is argued that it comes as a natural side effect of a complex, diversified, heterogeneous academia (Cimini et al. 2014). For this to happen, courage to broaden the understanding of the importance of allowing researchers to generate 
theory 'out of the box' is first required by academics themselves. Single academics and their research centres may need to act in novel ways, to question held beliefs and values. They may dare to balance between self-critiquing and the daring to question and articulate views counter to existing orthodoxies, to role-model the importance and the praxis of academic freedom and a commitment to uncompromising commitment to integrity (Rogers 1964, Koehn 2005, Akrivou 2008). They may need to keep demonstrating their integrity via doing what is the right thing irrespectively of this being not encouraged by current habitus, despite the fear and even warnings by management regarding academic promotion and tenure prospects. This is the careful nurturing of their research in slow, systematic, multiple long-term and carefull publication progression, and focus against fears of scoring against departmental and managerial metrics. This researcher activism re-establishes ethics of dialogue and less instrumental and myopic action on how to generate knowledge supporting a sustainable and really common 'common good' for the many rather than a few. This new common good may be based on novel social scientific knowledge assumption and work with commitment to understand and resolve systemic issues in a coherent and integrated fashion involving multiple ethical, social, economic and political dimensions of knowing. We must shift the current habitus towards new ways of understanding and ways of valuing research, knowledge generation and the links to both academic freedom and integrity and longerterm system economic and social prosperity. Current habitus remaining uninterrupted may not generate serious knowledge to tackle current challenges facing the societies and economies on our continent and the planet.

However, a real possibility to transform neo-liberal habitus is present insofar as we review our passive stance and assumptions on the force of habitus on us. Advances across social, brain and humanistic studies realise that the very understanding of habitus dynamics may not necessarily be a deterministic, relativist or objectivist view of truth, but instead the experience of social and individual agency may be due to incomplete conceptions of how the world is (e.g. Gadamer 1965, Bernacer \& Murillo 2012, Akrivou \& Todorow 2014, Bernacer \& Murillo 2014). These works draw from Aristotle and virtue theory of society, brain and mind science, and philosophical dialogue and discourse ethics to show that with a change of our assumptions and commitments we can actively create the future in which we can all flourish, rather than habitually respond to existing stimuli of fragmentation and antagonism.

Also at a macro level, however, there is work to be done which requires major institutional actors to cocreate new habits and virtues around research publication, research evaluation, research funding, the spreading of new research via teaching, and of course the practices and conventions of academic freedom and academic tenure and career decisionmaking. There is a need to re-orient educational and scientific policy beyond an unreflective embracement of neo-liberal narrowly rational ways of valuing with the excessive use of metrics and ratings to a more in depth reflection on the real potential of different research kinds and their horizon for maturation. Key aspects of this change consist of three changes at the level of valuing of policy makers, governments and universities:

(1) Policy makers must choose to revisit assumptions on the nature of science, truth (Gadamer 1965) and scientific knowing in ways which allow them to consciously embrace of a clear ethical agenda, replacing a rhetoric an ideal of unbiased and objective academia with more integrity. This means that while short-term research often sponsored by status quo firms is highly rated and easily attracts funding because it is highly marketable, it is unlikely to really impact progress (Cimini et al. 2014, Moro-Martin 2014) as it does not generate much new understanding which can lead to a more humane, sustainable and prosperous development of societies with humans and eco-systems flourishing at its heart.

(2) In addition to the courage of academics to engage in scientific dialogue and action which defies and questions the current rules, against academic fears of narrowly scoring against existing metrics, broader types of courage are required. For example, scientific community journals (and journal editors) need to dare transcending their 'formulaic' rules around academic publications fit for each journal, to visibly allow for substantial diversity in published articles (Alvesson \& Gabriel 2013). Journals are made by academics for academics to share academic debates leading to the validation of existing theory and the creation of novel theories. Therefore, rather than sticking to formulaic rules for empirical or strong theoretical proof for anything that is being published (a way of valuing that privileges the status quo), journal editors should enable academic dialogue and the expression of novel ideas with greater respect of academic freedom and diversity. In ethical terms, new theory has a legitimate access right to publication in order to gradually improve and become empirically tested. 
(3) A conscious investment is neccessary to appoint in key institutional and policy roles people with the character and intellectual maturiry to catalyse change (Akrivou \& Bradbury-Huang 2011, 2014). This refers to individuals with the capacity for dialogic mutuality in their shared responsibility as guardians of truth and progress in society and the economy. For this an overall character integrity and maturity is necessary to catalyse such social and institutional governance reforms with research and academic freedom at the core. A major focus of these integrating catalysts in key educational and related institutions would be to work against the current habitus of fragmentation and antagonism across sciences, aiming to re-integrate scientific knowledge in the university with a focus on dialoguing directly with individual researchers to increase collaborative work on how to bring about a more humane economy which embraces both humanism and an eco-centric paradigm (Purser et al. 1995).

In fact, what is required is a sense of responsibility and courage (replacing fear, inertia and conformism) to dare to re-orient the rules and the ethics of research and the resulting tenure policies in academia.

\section{LITERATURE CITED}

Akrivou K (2008) Differentiation and integration in adult development: The influence of self complexity and integrative learning on self-integration. PhD dissertation, Case Western Reserve University, Cleveland, $\mathrm{OH}$

Akrivou K, Bradbury-Huang H (2011) Executive catalysts: predicting sustainable organizational performance amid complex demands. Leadersh Q 22:995-1009

Akrivou K, Bradbury-Huang H (2014) Educating integrated catalysts: transforming business schools toward ethics and sustainability. Acad Manag Learn Educ, doi:10. 5465/amle.2012.0343

Akrivou K, Todorow L (2014) A dialogic conception of habitus: allowing human freedom and restoring the social basis of learning. Front Hum Neurosci 8:432

Alvesson M, Gabriel Y (2013) Beyond formulaic research: in praise of greater diversity in organizational research and publications. Acad Manag Learn Educ 12: 245-263

Bennis WG, O'Toole J (2005) How business schools lost their way. Harv Bus Rev 83:96-104

Editorial responsibility: Konstantinos Stergiou, Thessaloniki, Greece
Bernacer J, Murillo J (2012) An incomplete theory of the mind. Front Psychol 3:418

Bernacer J, Murillo J (2014) The Aristotelian conception of habit and its contribution to human neuroscience. Front Hum Neurosci 8:883

Boje DM (1993) The resurrection of Taylorism: total quality management's hidden agenda. J Organ Chang 69:335-344

Bourdieu P (2005) The social structures of the economy. Polity Press, Cambridge

Bourdieu P, Waquant L (1992) An invitation to reflexive sociology. University of Chicago Press, Chicago, IL

Chia R, Holt R (2008) The nature of knowledge in business schools. Acad Manag Learn Educ 7:471-486

Chomsky N (1999) Profit over people. Seven Stories Press, New York, NY

Cimini G, Gabrielli A, Labini FS (2014) The scientific competitiveness of nations. PLoS ONE 9:e113470

Davies W (2014) The limits of neo-liberalism. Sage Publications, London

Flyvbjerg B (2001) Making social sciences matter: why social inquiry fails and how it can succeed again. Oxford University Press, Oxford

Gadamer HG (1965) Truth and method. Crossroad, New York, NY

Ghoshal S (2005) Bad management theories are destroying good management practices. Acad Manag Learn Educ 4: 75-91

Greenwood D (2012) Doing and learning action research in the neo-liberal world of contemporary higher education. Action Res 10:115-132

Koehn D (2005) Integrity as a business asset. J Bus Ethics 58: 125-136

Kuhn TS (2012) The structure of scientific revolutions. University of Chicago Press, Chicago, IL

Mingers J, Willmott H (2012) Taylorizing business school research: on the 'One Best Way' performative effects of journal ranking lists. Human Relations 66:1051-1073

Moro-Martin A (2014) A call to those who care about Europe's science. Nature 151:141-142

> Pauly D (2014) Homo sapiens: cancer or parasite? Ethics Sci Environ Polit 14:7-10

Pfeffer J, Fong CT (2002) The end of business schools? Less success than meets the eye. Acad Manag Learn Educ 1: 78-95

Pfeffer J, Fong CT (2004) The business school 'business': some lessons from the US experience. J Manage Stud 41: 1501-1520

$>$ Purser RE, Park C, Montuori A (1995) Limits to anthropocentrism: toward an eco-centric organization paradigm? Acad Manage Rev 20:1053-1089

Rogers CR (1964) Toward a modern approach to values: the valuing process in the mature person. J Abnorm Psychol 68:160-167

Sandel MJ (2010) Justice. Penguin Books, London

Stergiou K, Tsikliras AC (2014) Global university rankings uncovered: introduction Ethics Sci Environ Polit 13:59-64

Submitted: November 12, 2014; Accepted: January 7, 2015

Proofs received from author(s): February 25, 2015 